\title{
Acta Psychiatrica Scandinavica
}

\section{Pramipexole in the treatment of unipolar and bipolar depression. A systematic review and meta-analysis.}

\begin{tabular}{|c|c|}
\hline Journal: & Acta Psychiatrica Scandinavica \\
\hline Manuscript ID & ACP-2019-8048.R1 \\
\hline Manuscript Type: & Systematic Review or Meta-analysis \\
\hline $\begin{array}{r}\text { Date Submitted by the } \\
\text { Author: }\end{array}$ & $\mathrm{n} / \mathrm{a}$ \\
\hline Complete List of Authors: & $\begin{array}{l}\text { Tundo, Antonio; Istituto di Psicopatologia, Clinical Psychiatry } \\
\text { de Filippis, Rocco; Istituto di Psicopatologia, Clinical Psychiatry } \\
\text { De Crescenzo, Franco; University of Oxford Department of Psychiatry, } \\
\text { Department of Psychiatry; Ospedale Pediatrico Bambino Gesu, Pediatric } \\
\text { University Hospital-Department }\end{array}$ \\
\hline Keywords: & Depression, Treatment, Review of the literature \\
\hline
\end{tabular}

\section{SCHOLARONE \\ Manuscripts}


Pramipexole in the treatment of unipolar and bipolar depression. A systematic review and meta-analysis.

Antonio Tundo ${ }^{1 *}$, Rocco de Filippis ${ }^{1}$, Franco De Crescenzo ${ }^{2,3,4}$.

${ }^{1}$ Istituto di Psicopatologia, via Girolamo da Carpi 1, 00196 Rome, Italy.

${ }^{2}$ Department of Psychiatry, University of Oxford, Oxford, United Kingdom.

${ }^{3}$ Pediatric University Hospital-Department (DPUO), Bambino Gesù Children's Hospital, Rome, Italy.

${ }^{4}$ Department of Epidemiology, Lazio Regional Health Service, Rome, Italy.

\section{*Corresponding author:}

Dr Antonio Tundo

Istituto di Psicopatologia

Via Girolamo da Carpi, 100196 Rome, Italy

Tel: +39063610955

E-mail: tundo@istitutodipsicopatologia.it

Running Head: Pramipexole for unipolar and bipolar depression. 


\begin{abstract}
Objective: Several depressed patients do not respond to traditional antidepressants. Our aim was to systematically review the effectiveness and safety of pramipexole in unipolar and bipolar depression.
\end{abstract}

Methods: We conducted a systematic review of randomised clinical trials (RCTs) and observational studies on pramipexole for patients with major depressive episodes, following PRISMA guidelines. Our primary outcome measure was response to therapy, measured at study endpoint. The study protocol was registered on PROSPERO: CRD42018108699.

Results: We found five RCTs, three open label trials and five observational studies, in 504 participants (57\% women; mean age, 45.3 years; mean sample size, 39; median duration of treatment, 8 weeks; mean duration of longest follow-up, 45 weeks; mean maximum dose, $1.62 \mathrm{mg}$ ). We found for pramipexole an overall short-term response rate of $52.2 \%$ and remission rate of $36.1 \%$, and an overall long-term response rate of $62.1 \%$ and remission rate of $39.6 \%$. Individuals on pramipexole, in RCTs, had a superior response rate to placebo (RR: 1.77; 95\%CI: 1.11 to 2.82) and similar to SSRIs (RR: 0.93 ; 95\%CI: 0.44 to 1.95 ). Acceptability and tolerability were good, with nausea being the most frequent side effect.

Conclusion: Our study found some evidence for an effect of pramipexole for the treatment of major depressive episodes.

Keywords: pramipexole, affective disorders, major depressive episode, treatment, systematic review. 


\section{Summations}

1. Results from clinical trials found that pramipexole for major depressive episodes is superior to placebo and similar to SSRIs.

2. The use of pramipexole as antidepressant appears to be safe, with nausea being the most frequent side effect.

3. Some side effects commonly reported in studies on individuals with Parkinson's disease such as lethargy, gambling, hypersexuality and compulsive shopping- are not reported in individuals treated with pramipexole for major depressive episodes.

\section{Limitations}

1. Only few studies were included in our systematic review.

2. The small sample sizes of the studies suggest that we are in an early phase of research and that a phase 3 trial is needed before coming to any clinically applicable conclusion. 


\section{Introduction}

Major depressive disorder (MDD) and bipolar disorder (BD), are the most frequent psychiatric disorders in the general population, with a lifetime prevalence of $20.8 \%{ }^{1}$, and a leading cause of premature death and ongoing disability ${ }^{2}$. Major depressive episode (MDE) is the cornerstone of the diagnosis of MDD and the most frequent presentation of $\mathrm{BD}^{3,4}$. The pharmacological treatment of MDE includes selective serotonin reuptake inhibitors (SSRIs), serotonin and noradrenaline reuptake inhibitors (SNRIs), noradrenergic and specific serotonergic antidepressants (NaSSAs), monoamine oxidase inhibitors (MOAIs), tricyclic antidepressants (TCAs) and newer atypical antidepressants, in monotherapy for unipolar depression ${ }^{5,6}$. In bipolar depression, antidepressants may be used in combination with mood stabilisers or second-generation antipsychotics for a subtype of patients (i.e., without mixed features, mood instability, rapid cycling course and (hypo)manic switch emerging during antidepressant treatment $)^{7,8,9}$. Although these different options, the treatment of MDE is still particularly challenging because of the high non-responder rate. For example, the STAR*D study found that $60-70 \%$ of patients with depressive episodes within MDD do not achieve symptomatic remission after first-line antidepressants ${ }^{10}$, while the STEP-BD study did not find any benefit in treating patients with bipolar depression by using antidepressants added on to mood stabilizers ${ }^{11}$. Given the limited efficacy of traditional antidepressants (ADs), the search for new and more effective treatments acting on monoamines different from serotonin and/or norepinephrine is ongoing, particularly for treatment-resistant depression ${ }^{12}$. Pramipexole, which is FDA-approved for the treatment of Parkinson's disease ${ }^{13}$ and restless legs syndrome ${ }^{14}$, is a non-ergot dopamine agonist with high affinity for the D2, D3, and D4 dopamine receptors and a very low affinity for 5HT2A and 5-HT2B receptors, and D1-type receptors ${ }^{15}$. Its preferential affinity for the D3 receptor subtype, showed in the preclinical studies, provides a rationale for the treatment of depression ${ }^{16}$. D3 receptors are densely distributed in the mesolimbic system, which has been implicated in the motoric and hedonic deficits in depression ${ }^{17,18}$. In the last 15 years, substantial efforts have been made to evaluate the efficacy and the safety of pramipexole for the treatment unipolar and bipolar depression, both in monotherapy and as adjunctive treatment. The available reviews focused on a limited number of trials ${ }^{19}$, or on randomized controlled trials (RCTs) ${ }^{20,21}$, or on trials including only patients with bipolar depression ${ }^{22}$.

\section{Aims of the study}

Our aim was to systematically review evidence of short and long-term efficacy, acceptability and tolerability of pramipexole in treating unipolar and bipolar depression. 
The protocol for this review was registered on PROSPERO international prospective register of systematic reviews (CRD42018108699) and it is available from the following link: https://www.crd.york.ac.uk/prospero/display_record.php?RecordID=108699

\section{Methods}

\section{Literature search}

A comprehensive computer literature search of the PubMed/MEDLINE, Cochrane Central Register of Controlled Trials (CENTRAL), Embase, databases was carried out to find relevant peer reviewed articles on the effect of pramipexole for major depressive episodes in mood disorders. The search syntax was based on combinations of the terms: mood disorders, depression, affective symptoms, affective disorder*, mood disorder*, bipolar, mania, manic, hypomani*, rapid cycling, continuous $\mathrm{cycl}^{*}$, pramipexole, dopamine agonists.

No beginning date limit and no language restrictions were used and the search was continued to 6 December 2018. We searched for ongoing and unpublished studies via Internet searches on ClinicalTrials.gov (www.clinicaltrials.gov) and on the World Health Organization (WHO) International Clinical Trials Registry Platform (ICTRP) (apps.who.int/trialsearch/) (see in the supplementary materials, appendix 1).

\section{Types of study included}

Clinical studies, either observational or experimental, on pramipexole for the depressive phase treatment of MDD and BD were included.

\section{Population}

Patients aged 18 or older, of both genders, with a primary diagnosis of unipolar or bipolar depression were included. A concurrent secondary diagnosis of another psychiatric disorder was not considered as an exclusion criterion. A concurrent primary diagnosis of a mental health condition was not an exclusion criterion. Studies in patients with mood disorder and with a concurrent serious medical illness were excluded.

\section{Intervention(s), exposure(s)}

Randomised clinical trials (RCTs) as well as retrospective or prospective observational short and long-term studies using pramipexole as monotherapy or in an augmentation strategy in major depressive episodes in either MDD or BD were included. 


\section{Primary outcome}

Our primary efficacy outcome measure was the treatment response, defined as a reduction of at least $50 \%$ from baseline on the Montgomery-Asberg Depression Rating Scale (MADRS) ${ }^{23}$ or Hamilton Depression Rating Scale (HDRS) ${ }^{24}$, or Clinical Global Impression-severity (CGI-S) ${ }^{25}$.

\section{Secondary outcomes}

As secondary outcomes we considered:

1) Remission, defined as a sub-threshold score on a depression scale (i.e. a score of seven or less on the HDRS-17) and calculated on the primary endpoint.

2) Score on MADRS or HDRS or CGI for the acute response (6-12 weeks). If neither of the former scales was used, we considered other clinician-rated and standardized rating scales

3) Score on MADRS or HDRS or CGI for the longest follow-up. In case no continuous outcome was used, we reported dichotomous outcomes (response/remission) to assess efficacy at the longest follow-up.

3) Tolerability, defined as the number of patients who discontinued the study due to any side effect, and the number and types of side-effects.

4) Acceptability, defined as the number of patients who discontinued the study due to any reason.

\section{Data extraction}

Two reviewers (RdF and FDC) independently read each article, evaluated the completeness of the data abstraction, and assessed the quality rating. We designed and used a structured data abstraction form to ensure consistency of appraisal for each study. Information extracted included study characteristics (such as lead author, publication year, journal), participant characteristics (age range, setting, diagnosis), intervention details (such as dose ranges, mean doses of study drugs) and outcome measures of interest. Data were extracted directly from the manuscript or from the tables when possible, and we used PlotDigitizer 2.6.8 ${ }^{26}$ to extract data from figures. Data on the primary and secondary outcomes were extracted by the same two researchers independently and disagreements were resolved in a consensus meeting or by a third reviewer.

\section{Statistical analysis}

We performed meta-analyses using random-effects model to estimate pooled risk ratios (RRs) for dichotomous outcomes and standardized mean differences (SMDs) for continuous outcomes with their 95\% confidence intervals (CIs) using STATA 13.1. We used SMDs as opposed to mean differences, because different mood scales were used in the studies. In interpreting SMD values, we 
considered SMD "small" if $<0.40$, "moderate" from 0.40 to 0.70 , and "large" if $>0.727$.

Heterogeneity between studies has been investigated by the I-squared statistic ${ }^{28}$ (I-squared equal to or more than $50 \%$ was considered indicative of heterogeneity), and by visual inspection of the forest plots. The quality of included studies was assessed using the Newcastle-Ottawa scale (for cohort studies ${ }^{29}$ and the Cochrane tool for risk of bias (for RCTs) ${ }^{27}$.

We performed subgroup analyses for pramipexole versus placebo and versus SSRIs for individuals with major depressive episodes in MDD and in BD.

\section{Results}

\section{Selected studies}

The database search generated 876 records and 309 other records were identified from searching trial registers. After the removal of duplicates through EndNote, a total of 1158 titles and abstracts were assessed. A total of 1133 articles were excluded from the title and abstract and 25 articles were retrieved in full text. Of these, two studies were excluded because letters to the editor, three studies were excluded because case reports, two studies were excluded because trials on individuals with bipolar disorder in euthymic phase, two were reviews, while one was a clinical trial on individuals with bipolar disorder treated with quetiapine extended release and pramipexole, but did not disclose results. The full reference list of excluded studies is in the supplementary material (see appendix 2). Finally, 15 articles, describing 13 studies (504 participants) were included in a qualitative synthesis, while five RCTs (316 participants) were included in the meta-analysis (see flow chart as Figure 1).

\section{Study characteristics}

The characteristics of the included studies are presented in Table 1. Five studies were RCTs, three were open label trials, one was a prospective observational study, three were chart reviews, and one study was a case series. The mean study sample size was 39, ranging between 10 and 174 participants. The median duration of treatment was 8 weeks (range 6-69). A total of five observational studies had a long-term follow-up for a mean duration of 39 weeks (range 17-69). More than a half of the population were women (57\%) and the mean age was 45.3 years. A total of $69 \%$ of studies (9 of 13) used the DSM-IV or DSM-IV-TR for the diagnosis. About two-third of participants (362 of 504) had a diagnosis of MDD, while about one-third had a diagnosis of BD. All the studies included as outcomes standardised scales, such as MADRS, HDRS or CGI, apart from one ${ }^{30}$. Pramipexole was mostly used with flexible dose, apart from one study which used fixed dose ${ }^{31}$, and the mean maximum dose used was $1.62 \mathrm{mg}$ (range $0.69-2.18$ ). In most of the studies patients 
used additional medications such as antidepressants (11 studies) or mood stabilisers (8 studies) (see appendix 3).

\section{Outcome measures}

Results are described qualitatively in Table 2 and quantitatively (when data were available) in Table 3 and 4. Primary outcomes of RCTs were mostly focused on the acute phase treatment, while observational studies had longer study duration.

When all the studies were considered, we found for pramipexole an overall short-term response rate of $52.2 \%$ and remission rate of $36.1 \%$, and an overall long-term response rate of $62.1 \%$ and remission rate of $39.6 \%$.

The pooled overall weighted mean response and remission rates were in RCTs $40.8 \%$ (95\%CI: 38.7 to 42.8 ) and $26.1 \%$ (95\% CI: 23.0 to 29.3 ), respectively, and in observational studies $63.4 \%$ (95\%CI: 60.5 to 66.2$)$ and $46.3 \%$ (95\%CI: 41.3 to 51.3$)$, respectively.

The overall weighted mean rates for dropout due to any adverse events and due any reason were in RCTs $17.7 \%$ (95\%CI: 15.0 to 20.3 ) and $30.7 \%$ (95\%CI: 28.1 to 33.2 ), respectively, and in observational studies $16.7 \%$ (95\%CI: 14.8 to 18.5 ) and $27.9 \%$ (95\%CI: 25.8 to 30.0$)$, respectively. The overall mean change from baseline on the MADRS total scores after 6-12 weeks of treatment was -14.1 (95\%CI: -13.5 to -14.6$)$ in RCTs and -15.2 (95\%CI: -13.5 to -16.8$)$ in observational studies.

\section{Data analysis}

Five RCTs, comprising a total of 316 participants, were included in a quantitative data analysis comparing the efficacy of pramipexole versus placebo and versus SSRIs. Pooled effect sizes with 95\% confidence intervals are shown in Table 3.

Compared to placebo, individuals on pramipexole had a significant $77 \%$ increase of response and a non-significant $68 \%$ increase of remission. Pramipexole was superior to placebo also on the acute response assessed as a continuous outcome, with a large effect size. The comparisons were nonsignificant for dropout due to any adverse event and any cause.

Meta-analyses comparing pramipexole to SSRIs showed a non-significant difference for response, remission, acute response assessed as a continuous outcome and dropout due to any cause. Individuals on pramipexole had significantly more dropouts due to any adverse event than individuals on SSRIs.

Meta-analyses of adverse events collected in RCTs showed a significantly higher nausea for individuals on pramipexole versus placebo (OR 2.85; 95\%CI: 1.53 to 5.31 ) or versus SSRIs (OR 
4.54; $95 \% \mathrm{CI}: 1.72$ to 12.5 ) and a significantly lower itching for individuals on pramipexole versus placebo (OR: 0.09; 95\%CI: 0.01 to 0.81). All the other adverse events were similar between groups (see appendix 4). The most common adverse events (1-10\% of the overall sample) reported in both RCTs and observational studies are listed in appendix 5.

\section{Subgroup analyses}

The pre-planned subgroup analyses, including only RCTs differentiating individuals with unipolar and bipolar depression, are presented in Table 4. Compared to placebo, pramipexole shows a significant higher response rates in bipolar but not in unipolar subgroup. No significant differences in outcomes emerge comparing pramipexole to SSRIs in unipolar subgroup, while no study compared these two treatments in bipolar subgroup.

\section{Risk of bias (quality) assessment}

The quality assessment for RCTs is described by using the Cochrane risk of bias tool in appendix 6 while the quality assessment of cohort studies is described by using the Newcastle-Ottawa Scale in appendix 7. The studies at lower risk of bias are the most recent ones, which were reported in more detail. It is noteworthy to mention that there was a high rate of attrition bias as dropouts were high and not balanced across study arms.

\section{Discussion}

To our knowledge, this is the first study to systematically evaluate the efficacy, tolerability and acceptability of pramipexole for the short- and long-term treatment of unipolar and bipolar depression.

The overall short-term response and remission rates for pramipexole is similar to response and remission rates for traditional antidepressants found by a recent systematic review on major depression by Cipriani et al. ${ }^{32}$ (52.2\% and $36.1 \%$ versus $52.9 \%$ and $32.6 \%$, respectively). The overall long-term remission rate for pramipexole is higher than that reported in some studies for traditional antidepressants (39.6\% and $10-11 \%$, respectively) ${ }^{33,34}$.

Regarding RCTs, the efficacy of pramipexole was comparable to SSRIs and higher than placebo, although the difference versus placebo on remission rate was high (68\%) but not significant. The observational studies reported higher response and remission rates than those reported in RCTs. The difference in effect between observational studies and RCTs could be partly explained by differences on pramipexole prescription. Indeed, in observational studies pramipexole was prescribed in flexible and higher doses than in RCTs ${ }^{30,35}$. These results are supported by other 
authors $^{19}$, who stressed the importance of adequate dosage for pramipexole to exert its full effect. Observational studies reported higher response and remission rates than RCTs also for traditional antidepressants ${ }^{36,37}$. This is a trend reported in different fields of medicine and we believe it is increasingly important to report results from both RCTs and observational studies in assessing benefits and risks of a drug ${ }^{38,39,40}$.

The findings of the present study show that the use of pramipexole as antidepressant is safe. The rate of drop-out for pramipexole was not significantly different compared to placebo (for both dropouts due to any side effect and due to any reason) and SSRIs (for dropouts due to any reason) and comparable to the rate of drop-out found for traditional antidepressants, as reported by Cipriani et al. ${ }^{32}$ (dropouts due to any side effect: $9.6 \%$ and $10.4 \%$, respectively; dropouts due to any reason: $17.8 \%$ and $26.4 \%$, respectively). Nausea was the only side effect with a higher prevalence in pramipexole than placebo and SSRIs. Unexpectedly, studies on individuals treated with pramipexole for depression did not report some side effects commonly reported in studies on individuals treated with pramipexole for Parkinson's disease, such as lethargy, gambling, hypersexuality and compulsive shopping ${ }^{41}$. In our opinion, this difference might be due to the different neurobiological dysfunctions underlying depression and Parkinson's disease ${ }^{42,43}$ or to the relatively small number of patients with depression treated with pramipexole, not sufficient enough to infrequent adverse events. Corrigan et al ${ }^{31}$ reported a high drop-out rate due to side effects $(51.5 \%)$ for pramipexole by administering a high dosage ( $5 \mathrm{mg} /$ daily) with a short time titration (14 days). The high drop-out rate in this study would suggest that a slow titration could further improve the tolerability and the safety of pramipexole.

The only significant evidence emerging from the separate analysis in unipolar and bipolar subgroup is the better response to pramipexole than to placebo, without differences in the safety, in individuals with bipolar depression. We did not have the data to distinguish the effect between bipolar I and II phenotypes. Notably, in the studies reviewed for bipolar depression there was no difference between pramipexole and placebo for the possible switch to (hypo)mania. This finding is in accordance with the conclusion of a previous paper selectively reviewing the studies on the efficacy and safety of pramipexole use as adjunctive treatment in bipolar depression ${ }^{22}$. This result, if confirmed in further trials, could be clinically very relevant since the absence of a clearly effective and safe treatment for depressive episode in bipolar disorder ${ }^{44,45}$ and the never-ending debate about the use of traditional antidepressants in this condition ${ }^{7}$. In our opinion, the small number of studies and sample size could explain the conflicting results in unipolar depression subgroup where the efficacy of pramipexole was non-significantly different to both placebo and SSRIs. 


\section{Limitations}

The main limitation of the present systematic review is the small number of the studies and of the participants included. This limitation may have contributed to the lack of statistical significance in most of the outcomes. Further limitations are the heterogeneity between studies as regard design, diagnostic criteria, pramipexole dosage and outcome. However, in order to take into account heterogeneity and differences in small studies we analysed the data using a random-effects model, which is more conservative. Moreover, the meta-analyses of RCTs showed low heterogeneity, strengthening the validity of our results.

\section{Conclusion}

In conclusion, we found some evidence on the effectiveness of pramipexole for the treatment of major depressive episodes- particularly for bipolar depression. Pramipexole appeared also to be safe, with the nausea as the most frequent side effect.

The use of pramipexole as antidepressant in clinical practice is off-label and its prescription should be reserved to carefully selected patients with treatment resistant depression ${ }^{12,46}$ and without psychotic symptoms in the previous or in the index episode (this is because pro-dopaminergic agents could induce psychosis in vulnerable individuals). The prescription of pramipexole should be reserved to specialist centers ${ }^{5}$. Suitably powered RCTs need to confirm the effect on the maintenance at long-term, and to explore the potential risk of mixed features, (hypo)manic switch or rapid-cycling course in patients with bipolar depression. In addition, future studies on individual patient data analyses from clinical trials could determine the profile of candidate patient for pramipexole treatment in light of specific symptoms dimensions.

\section{Acknowledgements:}

None.

\section{Financial disclosure}

This study was funded by the Fondazione dell'Istituto di Psicopatologia Onlus, Rome, Italy. The founding sourse had no role in the study design, collection, analysis or interpretation of the data, preparation of the manuscript, or the decision to submit the paper for publication.

\section{Declaration of Interest:}

The authors declare no conflict of interest. The statistical analyses were performed by Dr F De Crescenzo. The protocol for this review was registered on PROSPERO international prospective 
register of systematic reviews (CRD42018108699) in August 2018 and it is available from the following link: http://www.crd.york.ac.uk/PROSPERO/display record.php?ID=CRD42018108699

Table 1. Table of included studies.

Table 2. Table of results.

Table 3. Data analysis results from randomized controlled trials on individuals with major depressive episodes comparing pramipexole to placebo or SSRIs.

Table 4. Subgroup analyses from randomized controlled trials on individuals with major depressive episodes in MDD and in BD comparing pramipexole to placebo or SSRIs.

Figure 1. Flow chart.

Appendix 1. Search strategy.

Appendix 2. References of included and excluded studies.

Appendix 3. Table of additional treatments.

Appendix 4. Meta-analysis of adverse events collected in randomized clinical trials.

Appendix 5. List of the most common (1-10\%) adverse events reported for pramipexole considering both RCTs and observational studies.

Appendix 6. Risk of bias table for assessing the quality of cohort studies by using the NewcastleOttawa Scale.

Appendix 7. Risk of bias table for assessing the quality of randomised clinical trials by using the Cochrane risk of bias tool. 


\section{References}

[1] Kessler RC, Berglund P, Demler O, Jin R, Merikangas KR, Walters EE. Lifetime prevalence and age-of-onset distributions of DSM-IV disorders in the National Comorbidity Survey Replication. Arch Gen Psychiatry 2005;62:593-602.

[2] GBD 2016 Disease and Injury Incidence and Prevalence Collaborators. Global, regional, and national incidence, prevalence, and years lived with disability for 328 diseases and injuries for 195 countries, 1990-2016: a systematic analysis for the Global Burden of Disease Study 2016. Lancet 2017;390:1211-1259.

[3] Judd LL, Akiskal HS, Schettler PJ, Coryell W, Endicott J, Maser JD et al. A prospective investigation of the natural history of the long-term weekly symptomatic status of bipolar II disorder. Arch Gen Psychiatry 2003;60:261-269.

[4] Judd LL, Akiskal HS, Schettler PJ, Endicott J, Maser J, Solomon DA et al. The long-term natural history of the weekly symptomatic status of bipolar I disorder. Arch Gen Psychiatry 2002;59:530-537.

[5] Cleare A, Pariante CM, Young AH, Anderson IM, Christmas D, Cowen PJ et al. Evidencebased guidelines for treating depressive disorders with antidepressants: A revision of the 2008 British Association for Psychopharmacology guidelines. J Psychopharmacol 2015;29:459-525.

[6] National Institute for Health and Care Excellence (NICE). Depression in adults: recognition and management, Clinical guideline [CG90]. London: NICE; 2009. Last updated: April 2018.

[7] Pacchiarotti I, Bond DJ, Baldessarini RJ, Nolen WA, Grunze H, Licht RW et al. The International Society for Bipolar Disorders (ISBD) task force report on antidepressant use in bipolar disorders. Am J Psychiatry 2013;170:1249-1262.

[8] Yatham LN, Kennedy SH, Parikh SV, Schaffer A, Beaulieu S, Alda M et al. Canadian Network for Mood and Anxiety Treatments (CANMAT) and International Society for Bipolar Disorders (ISBD) collaborative update of CANMAT guidelines for the management of patients with bipolar disorder: update 2013. Bipolar Disord 2013;15:1-44. 
[9] Tundo A, Calabrese JR, Proietti L, de Filippis R. Short-term antidepressant treatment of bipolar depression: are ISBD recommendations useful in clinical practice? J Affect Disord 2015; 171:155-160.

[10] Trivedi MH, Rush AJ, Wisniewski SR, Nierenberg AA, Warden D, Ritz L et al. Evaluation of outcomes with citalopram for depression using measurement-based care in STAR*D: implications for clinical practice. Am J Psychiatry 2006;163:28-40.

[11] Bowden CL, Perlis RH, Thase ME, Ketter TA, Ostacher MM, Calabrese JR et al. Aims and results of the NIMH systematic treatment enhancement program for bipolar disorder (STEPBD). CNS Neurosci Ther 2012;18:243-249.

[12] Tundo A, de Filippis R, Proietti L. Pharmacologic approaches to treatment resistant depression: Evidences and personal experience. World J Psychiatry 2015;5:330-341.

[13] Antonini A, Barone P, Ceravolo R, Fabbrini G, Tinazzi M, Abbruzzese G. Role of pramipexole in the management of Parkinson's disease. CNS Drugs 2010;24:829-841.

[14] Aurora RN, Kristo DA, Bista SR, Rowley JA, Zak RS, Casey KR et al. The treatment of restless legs syndrome and periodic limb movement disorder in adults--an update for 2012: practice parameters with an evidence-based systematic review and meta-analyses: an American Academy of Sleep Medicine Clinical Practice Guideline. Sleep 2012;35:1039-1062.

[15] Antonini A, Calandrella D. Pharmacokinetic evaluation of pramipexole. Expert Opin Drug Metab Toxicol 2011;7:1307-1314.

[16] Maj J, Rogoi Z, Margas W, Kata M, Dziedzicka-Wasylewska M. The effect of repeated treatment with pramipexole on the central dopamine D3 system. J Neural Transm (Vienna) 2000;107:1369-1379.

[17] Russell JM, Hawkins K, Ozminkowski RJ, Orsini L, Crown WH, Kennedy S, et al. The cost consequences of treatment-resistant depression. J Clin Psychiatry 2004;65(3): 341-347.

[18] Dunlop BW, Nemeroff cb. The role of dopamine in the pathophysiology of depression. Arch Gen Psychiatry 2007; 64: 327-37. 
[19] Cowen PJ. Backing into the future: pharmacological approaches to the management of resistant depression. Psychol Med 2017;47:2569-2577.

[20] Kleeblatt J, Betzler F, Kilarski LL, Bschor T, Kohler S. Efficacy of off-label augmentation in unipolar depression: A systematic review of the evidence. Eur Neuropsychopharmacol 2017;27:423-441.

[21] Romeo B, Blecha L, Locatelli K, Benyamina A, Martelli C. Meta-analysis and review of dopamine agonists in acute episodes of mood disorder: Efficacy and safety. J Psychopharmacol 2018;32:385-396.

[22] Dell'Osso B, Ketter TA. Assessing efficacy/effectiveness and safety/tolerability profiles of adjunctive pramipexole in bipolar depression: acute versus long-term data. Int Clin Psychopharmacol 2013;28:297-304.

[23] Montgomery SA, Asberg M. A new depression scale designed to be sensitive to change. $\mathrm{Br}$ J Psychiatry 1979;134:382-389.

[24] HAMILTON M. A rating scale for depression. J Neurol Neurosurg Psychiatry. 1960;23:5662.

[25] Guy W. Clinical Global Impressions (CGI) Scale, Modified. In Rush, John A.; Task Force for the Handbook of Psychiatric Measures. Handbook of Psychiatric Measures (1st ed.). Washington, DC: American Psychiatric Association. 2000.

[26] Huwaldt JA. Plot Digitzer (Version 2.6.8), 2001. Available at: http://plotdigitizer.sourceforge.net

[27] Higgins J, Green S. Cochrane handbook for systematic reviews of interventions version 5.1.0. The Cochrane Collaboration. 2011. Available from: www.cochrane-handbook.org [28] Higgins JP, Thompson SG, Deeks JJ, Altman DG. Measuring inconsistency in metaanalyses. BMJ 2003;327:557-560. 
[29] Wells GA, Shea B, O'Connell D, Peterson J, Welch V, Losos M, et al. The Newcastle Ottawa scale (NOS) for assessing the quality of nonrandomised studies in meta-analysis. 2011. Available from: http://www.ohri.ca/programs/clinical_epidemiology/oxford.asp

[30] Fawcett J, Rush AJ, Vukelich J, Diaz SH, Dunklee L, Romo P et al. Clinical Experience With High-Dosage Pramipexole in Patients With Treatment-Resistant Depressive Episodes in Unipolar and Bipolar Depression. Am J Psychiatry 2016;173:107-111.

[31] Corrigan MH, Denahan AQ, Wright CE, Ragual RJ, Evans DL. Comparison of pramipexole, fluoxetine, and placebo in patients with major depression. Depress Anxiety 2000;11:58-65.

[32] Cipriani A, Furukawa TA, Salanti G, Chaimani A, Atkinson LZ, Ogawa Y, et al. Comparative efficacy and acceptability of 21 antidepressant drugs for the acute treatment of adults with major depressive disorder: a systematic review and network meta-analysis. Lancet. 2018;391:1357-1366.

[33] Rush AJ, Trivedi M, Carmody TJ, Biggs MM, Shores-Wilson K, Ibrahim H et al. One-year clinical outcomes of depressed public sector outpatients: a benchmark for subsequent studies. Biol Psychiatry 2004;56:46-53.

[34] Pigott HE, Leventhal AM, Alter GS, Boren JJ. Efficacy and effectiveness of antidepressants: current status of research. Psychother Psychosom 2010;79:267-279.

[35] Hori H, Kunugi H. The efficacy of pramipexole, a dopamine receptor agonist, as an adjunctive treatment in treatment-resistant depression: an open-label trial. Scientific World Journal 2012;2012:372474.

[36] Vandenbroucke JP. Why do the results of randomised and observational studies differ? BMJ 2011;343:d7020.

[37] Hughes-Morley A, Young B, Waheed W, Small N, Bower P. Factors affecting recruitment into depression trials: Systematic review, meta-synthesis and conceptual framework. J Affect Disord 2015;172:274-290. 
[38] Benson K, Hartz AJ. A comparison of observational studies and randomized, controlled trials. N Engl J Med 2000;342:1878-1886.

[39] Faraoni D, Schaefer ST. Randomized controlled trials vs. observational studies: why not just live together? BMC Anesthesiol 2016;16:102-016-0265-3.

[40] Lee H, Song S, Oh YK, Kang W, Kim E. Is gender still a predisposing factor in contrastmedia associated adverse drug reactions? A systematic review and meta-analysis of randomized trials and observational studies. Eur J Radiol 2017;89:81-89.

[41] Shen T, Ye R, Zhang B. Efficacy and safety of pramipexole extended-release in Parkinson's disease: a review based on meta-analysis of randomized controlled trials. Eur J Neurol 2017;24:835-843.

[42] Aiken CB. Pramipexole in psychiatry: a systematic review of the literature. J Clin Psychiatry 2007;68:1230-1236.

[43] Czernecki V, Pillon B, Houeto JL, Pochon JB, Levy R, Dubois B. Motivation, reward, and Parkinson's disease: influence of dopatherapy. Neuropsychologia 2002;40:2257-2267.

[44] Young LT. What is the best treatment for bipolar depression? J Psychiatry Neurosci 2008;33:487-488.

[45] Tundo A, Cavalieri P, Navari S, Marchetti F. Treating bipolar depression - antidepressants and alternatives: a critical review of the literature. Acta Neuropsychiatr 2011;23:94-105.

[46] Kennedy SH, Lam RW, McIntyre RS, Tourjman SV, Bhat V, Blier P et al. Canadian Network for Mood and Anxiety Treatments (CANMAT) 2016 Clinical Guidelines for the Management of Adults with Major Depressive Disorder: Section 3. Pharmacological Treatments. Can J Psychiatry 2016;61:540-560. 
Table 1. Characteristics of studies included in meta-analyses.

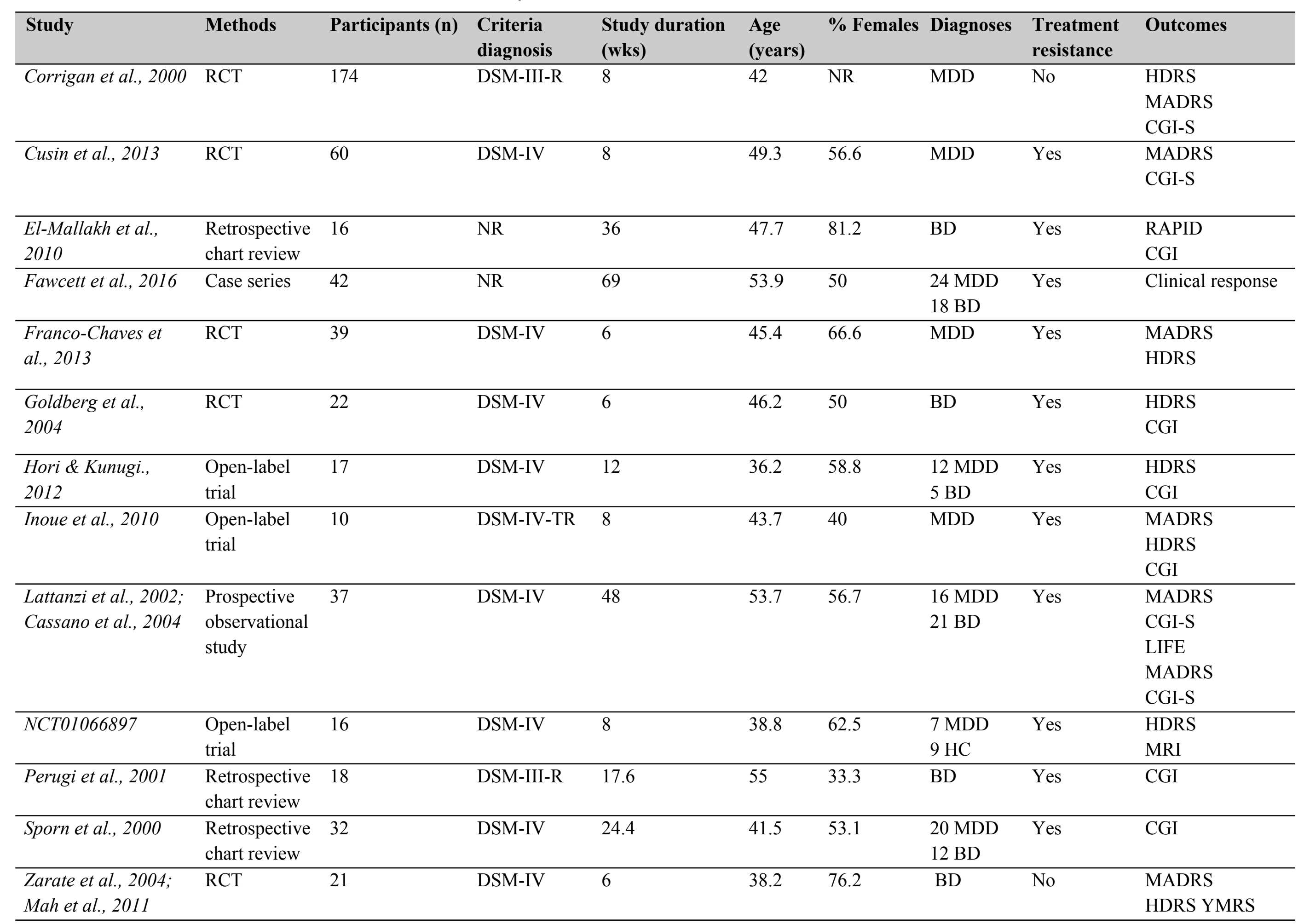

Notes: $\mathrm{BD}=$ bipolar disorder; $\mathrm{CGI}-\mathrm{S}=$ clinical global impression-severity; $\mathrm{ESCI}=$ escitalopram; FLX= fluoxetine; HDRS= Hamilton depression rating scale; MADRS= Montgomery-Asberg Depression Rating Scale; $\mathrm{MDD}=$ major depressive disorder; $\mathrm{NR}=$ not reported; $\mathrm{PBO}=$ placebo; $\mathrm{PPX}=$ pramipexole; $\mathrm{RAPID}=$ rapid psychiatric interview data; $\mathrm{RCT}=$ randomised controlled trial; YMRS= Young mania rating scale. 
Table 2. Table of results.

\begin{tabular}{|c|c|c|c|c|c|c|c|c|c|}
\hline Study & $\begin{array}{l}\text { Partici } \\
\text { pants }\end{array}$ & $\begin{array}{l}\text { Treatmen } \\
\text { t }(\mathrm{mg})\end{array}$ & $\begin{array}{l}\text { Respons } \\
\text { e n }(\%)\end{array}$ & $\begin{array}{l}\text { Remissi } \\
\text { on n (\%) }\end{array}$ & $\begin{array}{l}\text { Dropouts due } \\
\text { to any adverse } \\
\text { event } n(\%)\end{array}$ & $\begin{array}{l}\text { Dropouts } \\
\text { due to any } \\
\text { cause } n(\%)\end{array}$ & $\begin{array}{l}\text { Baseline Scale } \\
\text { MADRS (SD) }\end{array}$ & $\begin{array}{l}\text { Acute phase } \\
\text { response 6-12 } \\
\text { wks } \\
\text { MADRS (SD) }\end{array}$ & $\begin{array}{l}\text { Results at follow } \\
\text { up }\end{array}$ \\
\hline \multicolumn{10}{|l|}{$R C T$} \\
\hline \multirow{5}{*}{$\begin{array}{l}\text { Corrigan et al., } \\
2000\end{array}$} & 36 & PPX: & 15 & - & 3 & 9 & $21.4(\mathrm{NR})^{*}$ & - & - \\
\hline & 35 & 0.375 & 13 & - & 5 & 12 & $22.0(\mathrm{NR})^{*}$ & - & - \\
\hline & 33 & PPX: 1 & 11 & - & 17 & 19 & $21.8(\mathrm{NR})^{*}$ & - & - \\
\hline & 35 & PPX: 5 & 17 & - & 1 & 3 & - & - & - \\
\hline & 35 & $\begin{array}{l}\text { FLX } 20 \\
\text { PBO }\end{array}$ & 9 & - & 4 & 11 & - & - & - \\
\hline \multirow[t]{2}{*}{ Cusin et al., 2013} & 30 & PBO & 8 & 7 & 4 & 10 & $27.2(5.8)$ & $19.6(18.0)$ & - \\
\hline & 30 & PPX:1.35 & 12 & 10 & 4 & 8 & $27.4(5.9)$ & $14.7(14.3)$ & - \\
\hline \multirow{4}{*}{$\begin{array}{l}\text { Franco-Chaves et } \\
\text { al., } 2013\end{array}$} & 13 & ESCI: 10 & 2 & 2 & 0 & 2 & $30.1(5.4)$ & $22.6(14.1)$ & - \\
\hline & 13 & PPX: 1.55 & 4 & 1 & 1 & 2 & $33.5(4.8)$ & $20.5(15.5)$ & \\
\hline & 13 & $\begin{array}{l}\mathrm{PPX}+\mathrm{ESC} \\
\mathrm{I}: 1.16\end{array}$ & 1 & 0 & 3 & 9 & $31.4(5.6)$ & $28.8(21.9)$ & - \\
\hline & & & & & & & & & - \\
\hline \multirow{2}{*}{$\begin{array}{l}\text { Goldberg et al., } \\
2004\end{array}$} & 10 & PBO & 2 & 1 & 0 & 0 & $19.3(4.7)^{*}$ & - & - \\
\hline & 12 & PPX: 1.7 & 8 & 2 & 0 & 1 & $20.2(5.9)^{*}$ & - & - \\
\hline Zarate et al., 2004; & 10 & PPX: 1.7 & 6 & 4 & 0 & 1 & $33.8(5.4)$ & $17.2(8.4)$ & \\
\hline Mah et al., 2011 & 11 & PBO & 1 & 1 & 0 & 1 & $31.9(3.4)$ & $27.6(7.7)$ & \\
\hline \multicolumn{10}{|c|}{ Observational studies } \\
\hline $\begin{array}{l}\text { El-Mallakh et al., } \\
2010\end{array}$ & 16 & PPX: 1.03 & 15 & 8 & 6 & 6 & $\begin{array}{l}17.8(7.0) \\
\text { RAPID }\end{array}$ & $\begin{array}{l}5.9(4.9) \\
\text { RAPID }\end{array}$ & 5.7 (4.8) RAPID \\
\hline Fawcett et al. 2016 & 42 & PPX: 2.18 & 32 & 20 & 8 & 15 & $\begin{array}{l}3.33(0.72) \\
\text { Clinical }\end{array}$ & - & $\begin{array}{l}76 \% \text { of patients } \\
\text { responded, } 47.6 \% \\
\text { remitted. }\end{array}$ \\
\hline $\begin{array}{l}\text { Hori \& Kunugi, } \\
2012\end{array}$ & 17 & PPX: 1.6 & 12 & 10 & 0 & 2 & $19.4(3.8)^{*}$ & $7.2(5.4)^{*}$ & - \\
\hline Inoue et al., 2010 & 10 & PPX: 1.3 & 6 & 6 & 2 & 2 & $23.9(7.0)$ & $12.9(13.6)$ & - \\
\hline $\begin{array}{l}\text { Lattanzi et al., } \\
\text { 2002; Cassano et } \\
\text { al., } 2004\end{array}$ & 37 & PPX: 0.95 & 21 & - & 5 & 12 & $33.3(8.4)$ & $13.9(11.5)$ & $\begin{array}{l}61 \% \text { of patients } \\
\text { completed } \\
\text { follow-up; } \\
47.8 \% \text { remitted } \\
\text { after } 13 \text { week and } \\
60.9 \% \text { remitted } \\
\text { after } 22 \text { week of }\end{array}$ \\
\hline
\end{tabular}




\begin{tabular}{|c|c|c|c|c|c|c|c|c|c|}
\hline & & & & & & & & & treatment \\
\hline NCT01066897 & 7 & $\begin{array}{l}\text { PPX: } 1.0- \\
1.5\end{array}$ & - & - & 2 & 2 & - & - & - \\
\hline Perugi et al., 2001 & 10 & PPX: 1.23 & 4 & 0 & - & - & - & - & $\begin{array}{l}5 / 6 \text { mild-marked } \\
\text { response }\end{array}$ \\
\hline Sporn et al., 2000 & 32 & PPX: 0.69 & 14 & - & 4 & 12 & - & - & $43.7 \%$ responded \\
\hline
\end{tabular}

Notes: $\mathrm{ESCI}=$ escitalopram; FLX= fluoxetine; $\mathrm{MADRS}=$ Montgomery-Asberg Depression Rating Scale; $\mathrm{PBO}=$ placebo; $\mathrm{PPX}=$ pramipexole; RAPID= rapid psychiatric interview data; $\mathrm{RCT}=$ randomised controlled trial; $* \mathrm{HDRS}=$ Hamilton depression rating scale. 
Table 3. Data analysis results from randomized controlled trials on individuals with major depressive episodes comparing pramipexole to placebo or SSRIs.

\section{Comparis}

on

Outcome

Pramipexole versus placebo

\begin{tabular}{|c|c|c|c|c|c|}
\hline Response (RR) & 4 & 1.77 & 1.11 to 2.82 & 2.42 & $\underline{0.019}$ \\
\hline Remission (RR) & 3 & 1.68 & 0.81 to 3.45 & 1.40 & 0.161 \\
\hline $\begin{array}{l}\text { Dropout due to adverse event } \\
\text { (RR) }\end{array}$ & 2 & 1.60 & 0.73 to 3.50 & 1.18 & 0.239 \\
\hline Dropout due to any cause (RR) & 4 & 1.08 & 0.70 to 1.68 & 0.36 & 0.719 \\
\hline Any scale acute (SMD) & 3 & -0.77 & $\begin{array}{l}-1.42 \text { to }- \\
0.13\end{array}$ & 2.35 & $\underline{0.019}$ \\
\hline
\end{tabular}

Pramipexole versus SSRIs

\begin{tabular}{|c|c|c|c|c|c|c|}
\hline Response (RR) & 2 & 0.931 & 0.44 to 1.95 & 0.19 & 0.850 & $29.1 \%$ \\
\hline Remission (RR) & 1 & 0.50 & 0.05 to 4.86 & 0.60 & 0.550 & . \\
\hline $\begin{array}{l}\text { Dropout due to adverse event } \\
\text { (RR) }\end{array}$ & 2 & 6.28 & $\begin{array}{l}1.19 \text { to } \\
33.00\end{array}$ & 2.17 & $\underline{0.030}$ & $0.0 \%$ \\
\hline Dropout due to any cause (RR) & 2 & 2.52 & $\begin{array}{l}0.60 \text { to } \\
10.55\end{array}$ & 1.27 & 0.205 & $48.2 \%$ \\
\hline Any scale acute (SMD) & 1 & -0.14 & -0.91 to 0.63 & 0.36 & 0.718 & . \\
\hline
\end{tabular}

Notes: $95 \% \mathrm{CI}=95 \%$ confidence interval; $\mathrm{I}^{2}=$ heterogeneity; $\mathrm{RR}=$ relative risk; $\mathrm{SMD}=$ standardised mean difference; SSRIs= selective serotonin reuptake inhibitors

\begin{tabular}{lllll}
$\begin{array}{l}\text { Effect } \\
\text { size }\end{array}$ & $95 \% \mathrm{CI}$ & $\mathrm{z}-$ & $\mathbf{p}-$ & $\mathbf{I}^{2}$ \\
& & score & value & \\
\hline
\end{tabular}

Studies

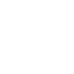


Table 4. Subgroup analyses from randomized controlled trials on individuals with major depressive episodes in MDD and in BD, comparing pramipexole to placebo or SSRIs.

\begin{tabular}{|c|c|c|c|c|c|c|c|}
\hline Comparison & Outcome & Studies & Effect size & $95 \% \mathrm{CI}$ & z-score & p-value & $\mathbf{I}^{2}$ \\
\hline \multicolumn{8}{|c|}{ Pramipexole versus placebo for $M D D$} \\
\hline & Response (RR) & 2 & 1.47 & 0.92 to 2.36 & 1.61 & 0.107 & $0.0 \%$ \\
\hline & Remission (RR) & 1 & 1.43 & 0.63 to 3.25 & 0.85 & 0.395 & . \\
\hline & $\begin{array}{l}\text { Dropout due to adverse event } \\
\text { (RR) }\end{array}$ & 2 & 1.60 & 0.73 to 3.49 & 1.18 & 0.239 & $0.0 \%$ \\
\hline & Dropout due to any cause (RR) & 2 & 1.06 & 0.68 to 1.66 & 0.27 & 0.786 & $0.0 \%$ \\
\hline & Any scale acute (SMD) & 1 & -0.30 & -0.81 to 0.21 & 1.16 & 0.246 & . \\
\hline \multicolumn{8}{|c|}{ Pramipexole versus placebo for $B D$} \\
\hline & Response (RR) & 2 & 4.12 & 1.40 to 12.15 & 2.57 & $\underline{0.010}$ & $0.0 \%$ \\
\hline & Remission (RR) & 2 & 2.85 & 0.64 to 12.81 & 1.37 & 0.171 & $0.0 \%$ \\
\hline & $\begin{array}{l}\text { Dropout due to adverse event } \\
\text { (RR) }\end{array}$ & $\cdot$ & $\cdot$ & $\cdot$ & . & $\cdot$ & $\cdot$ \\
\hline & Dropout due to any cause (RR) & 2 & 1.56 & 0.21 to 11.64 & 0.44 & 0.663 & $0.0 \%$ \\
\hline & Any scale acute (SMD) & 2 & -1.16 & $\begin{array}{l}-1.82 \text { to }- \\
0.51\end{array}$ & 3.49 & $\underline{0.000}$ & $0.0 \%$ \\
\hline \multicolumn{8}{|c|}{ Pramipexole versus SSRIs for MDD } \\
\hline & Response (RR) & 2 & 0.93 & 0.44 to 1.95 & 0.19 & 0.850 & $29.1 \%$ \\
\hline & Remission (RR) & 1 & 0.50 & 0.05 to 4.86 & 0.60 & 0.550 & . \\
\hline & $\begin{array}{l}\text { Dropout due to adverse event } \\
\text { (RR) }\end{array}$ & 2 & 6.28 & 1.19 to 33.00 & 2.17 & $\underline{0.030}$ & $0.0 \%$ \\
\hline & Dropout due to any cause (RR) & 2 & 2.52 & 0.60 to 10.55 & 1.27 & 0.205 & $48.2 \%$ \\
\hline & Any scale acute (SMD) & 1 & -0.14 & -0.91 to 0.63 & 0.36 & 0.718 & . \\
\hline
\end{tabular}

Notes: We did not find any study on Pramipexole versus SSRIs for bipolar disorder. 95\%CI=95\% confidence interval; BD= bipolar disorder; $\mathrm{I}^{2}=$ heterogeneity; $\mathrm{MDD}=$ major depressive disorder; $\mathrm{RR}=$ relative risk; $\mathrm{SMD}=$ standardised mean difference; $\mathrm{SSRIs}=$ selective serotonin reuptake inhibitors. 


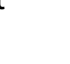




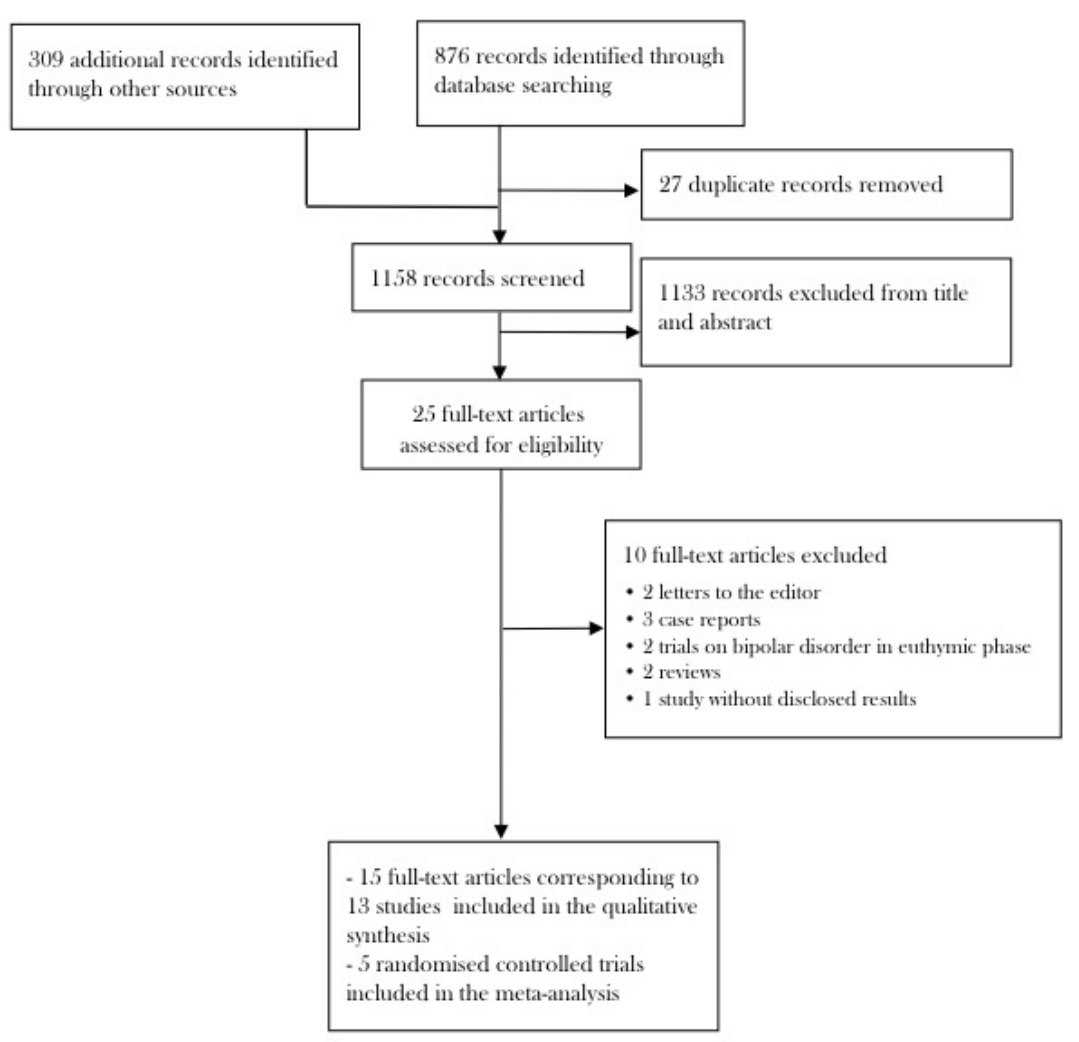

Flow chart.

$254 \times 280 \mathrm{~mm}(72 \times 72$ DPI $)$ 